\title{
Clinical Study on Hollow Viscus Perforation
}

Mali Nishkanth ${ }^{1 *}$, Likhitha $\mathrm{Sri}^{1}$, K. Lakshmana Murthy ${ }^{2}$

${ }^{1}$ Postgraduate, Department of General Surgery, Kamineni institute of medical sciences, Narketpally, Telangana, India

${ }^{2}$ Professor and Head of department, Department of General Surgery, Kamineni institute of medical sciences, Narketpally, Telangana, India

*Corresponding author: Mali Nishkanth

Introduction: Perforation of a hollow viscous from wide variety of causes comprises the major portion of emergency surgical admissions and emergency laparotomies. The spectrum of etiology of perforation in developing countries continues to be different from its western counterpart. In case of peritonitis due to hollow viscous perforation early surgery has got advantages over the late surgery. Omental patch repair and primary closures are some of the time tested procedures performed. Objectives: To study the age and sex distribution, anatomical distribution of hollow viscous perforation, operative procedure performed for various etiologies and post-operative complications of operative management. Methods: This is a retrospective study conducted in kamineni Institue of medical sciences, hospital and RC, Narketpally between January $1^{\text {st }} 2019$ and December $31^{\text {st }} 2019$ among patients diagnosed and operated for hollow viscous perforation. Results: In this retrospective study males comprised of $67.5 \%$ compared to females $(32.5 \%)$, the commonest age group involved is 41-50 years. The commonest anatomical site involved was that of duodenum followed by Gastric. The commonest operative procedure performed was omental patch closure technique. Large intestine and ileal perforation carried a high risk of post-operative surgical site infection and mortality.

Keywords: Perforation, hollow viscus perforation.

Copyright $(92020$ The Author(s): This is an open-access article distributed under the terms of the Creative Commons Attribution 4.0 International License (CC BY-NC 4.0) which permits unrestricted use, distribution, and reproduction in any medium for non-commercial use provided the original author and source are credited.

\section{INTRODUCTION}

Gastrointestinal perforation is a common medical emergency having a high morbidity and mortality $[1,2,8]$. Abdomen is a Pandora's Box and gastrointestinal perforation is one such condition to prove it. The different modes of presentation of cases may be misleading the diagnosis of its origin. Perforation of a hollow viscus from wide variety of causes comprises the major portion of emergency surgical admissions and emergency laparotomies [3, 4]. Significant morbidity and mortality results from diagnostic delay. Thus, an interest is undertaken to find the etiological factors and clinical features, age and gender incidence and also to assess the common type of perforations and their presentations, operative modalities, complications arising postoperatively.

The spectrum of etiology of perforation in developing countries continues to be different from its western counterpart. In contrast to western countries where lower gastro- intestinal tract perforations predominate, upper gastrointestinal tract perforations constitute the majority of cases in India $[5,6]$. Though proton pump inhibitors and antacids have largely decrease the peptic ulcer complications in western world they continue to make up a large chunk of hollow viscus perforation cases in developing nations.

Problem in North America and the U.K., where vascular lesions and malignancies are predominant cause of perforations, while in our country, peptic disease, typhoid, tuberculosis are still preceding malignancies. Smoking and use of nonsteroidal anti- inflammatory drugs are important risk factors for perforation.

The first clinical description of perforated peptic ulcer was made by Crisp in 1843.Diagnosis is usually made clinically and confirmed by the presence pneumoperitoneum on radiographs. The investigations should be such that it gives a definitive diagnosis in a short time. With the research and development in the field on surgery and intensive care facilities the treatment has swing towards operative approach compared to conservative approach. Sir Cuthbert Wallace puts it "it is better, to check than being waiting". In case of peritonitis i.e. Early surgery has got advantages over the late surgery. It is necessary to know the current surgical procedures for different perforation. 
Operative management consists of time honored practice of omental patch closure, but this can also be done by laparoscopic method. Ileal perforation is a common surgical emergency in the tropical countries. It is reported to constitute the 5th commonest cause of abdominal emergencies due to high incidence of enteric fever and tuberculosis in these countries. The mortality rate from Ileal perforations remains high in developing countries, despite improvement in critical care and timely surgical intervention ${ }^{7}$. In the presence of advanced anesthesia of today and tremendous improvement of resuscitative measures, every patient with Ileal perforation should be recommended for surgery.

Appendicitis if untreated, progress to local peritonitis with formation of gangrene of appendix, perforation and generalized peritonitis.

Acute mesenteric ischemia is a catastrophic surgical emergency with severe morbidity and mortality. In acute mesenteric ischemia, presence of peritoneal signs mandates surgical exploration along with embolectomy. In the absence of the peritoneal signs, embolectomy is the standard of care. Infusion of intraluminal vasodilator is done in non- occlusive mesenteric ischemia.

Colonic perforations which carries high mortality risk is mainly due to diverticular perforation but perforations due to neoplasm, ischemia is also seen. Perforation of the large intestine represents a major surgical challenge to the clinician, not simply because the technical aspects of the operation may be difficult but more importantly because the situation is rapidly lethal, in the type of compromising patients in whom the condition usually presents. Perforation of the large intestine is a rapidly fatal condition, death being caused by sepsis from peritoneal contamination with various enteric pathogens both aerobic and anaerobic. Iatrogenic perforation secondary to endoscopies (UGI and colonoscopy) are not uncommon. Perforation is also common in cancerous patients who have been previously treated with radiotherapy secondary to radiation enteritis. Now-a- days, operative management of peritonitis consists of simple closure of the perforation with a thorough peritoneal lavage and also resection and anastomosis if needed especially in small bowel perforation. In colon cancer with gross contamination of the peritoneum resection of the pathologic part with diversion procedure is considered.

\section{Gfrn utvAims and objectives}

- To study the age and gender distribution.

- To study the anatomical distribution of hollow viscous perforation.

- To study the commonest operative procedure performed for various etiologies.

- To study the post-operative complications of operative management.

- To study the overall mortality secondary to hollow viscus perforation.

\section{MATERIALS AND METHODS}

This is a retrospective study conducted in kamineni Institute of medical sciences and hospital, Narketpally between January $1^{\text {st }} 2019$ and December $31^{\text {st }} 2019$ comprising of patients who were diagnosed as a case of hollow viscus perforation confirmed by ultrasonography or radiography or computer tomography and surgery was performed.

\section{INVESTIGATIONS}

- Routine blood examination including complete hemogram, blood grouping and typing, Serology, blood urea, serum creatinine, serum electrolytes.

- Urine examination including albumin, sugar and deposits were done for the included subjects.

- $\quad$ Erect abdomen X-ray to detect free gas under diaphragm (lateral decubitus Xray in unstable patients),

- Widal test was done in suspected enteric perforations.

- Ultrasonography and CECT abdomen were also performed in selective cases.

\section{Inclusion Criteria}

All the patients who were diagnosed with hollow viscous perforation and underwent a surgery were included. Both sexes, age group above 18years.

\section{Exclusion Criteria}

Patients with peritonitis secondary to esophagus perforation and reproductive tract perforation were excluded.

\section{RESULTS}

Table-1: Distribution of patients based on gender

\begin{tabular}{|l|l|l|}
\hline Sex & Total $(\mathbf{n}=\mathbf{8 0})$ & Percentage \\
\hline Male & 54 & 67.5 \\
\hline Female & 26 & 32.5 \\
\hline
\end{tabular}

In this study, maximum number of patients was found to be males $54(67.5 \%)$ and the females constituted about $32.5 \%$ with 26 cases.

Table-2: Distribution of patients based on age

\begin{tabular}{|l|l|l|}
\hline AGE (YEARS) & NUMBER & PERCENT AGE \\
\hline $18-30$ & 09 & $11.25 \%$ \\
\hline $31-40$ & 14 & 17.5 \\
\hline $41-50$ & 26 & $32.5 \%$ \\
\hline $51-60$ & 19 & $23.5 \%$ \\
\hline$>60$ & 12 & $15 \%$ \\
\hline
\end{tabular}


In this study, most of the patients with hollow viscous perforation were age group 41- 50 years followed by the age group of 51-60 years group. The youngest patient in this study was 21 years who was having appendicular perforation and the oldest patient is of 68 years with perforation. Mean age is 42.6 years.

Table-3: Anatomical site of perforation

\begin{tabular}{|l|l|l|}
\hline Site of perforation & Number of cases & Percentage \\
\hline DUODENUM & 31 & $38.7 \%$ \\
\hline STOMACH & 19 & $23.7 \%$ \\
\hline ILEUM & 10 & $12.5 \%$ \\
\hline APPENDIX & 14 & $17.5 \%$ \\
\hline LARGE INTESTINE & 4 & $5 \%$ \\
\hline MULTIPLE SITES & 2 & $2.5 \%$ \\
\hline
\end{tabular}

The commonest site involved in hollow viscous perforation in this study was duodenal perforation $31(38.7 \%)$ followed by gastric perforation $19(23.7 \%)$ appendicular perforation $14(17.5 \%)$, and ileal perforation $10(12.5 \%)$.

Table-4: Surgical procedure Performed

\begin{tabular}{|l|l|l|}
\hline Surgical method & $\begin{array}{l}\text { Number of } \\
\text { cases }\end{array}$ & Percentage \\
\hline OMENTAL PATCH & 46 & $57.5 \%$ \\
\hline PRIMARY CLOSURE & 10 & $15 \%$ \\
\hline OSTOMIES & 7 & $8.75 \%$ \\
\hline APPENDICECTOMY & 14 & $17.5 \%$ \\
\hline $\begin{array}{l}\text { PRIMARY CLOSURE } \\
\text { +DIVERSION STOMA }\end{array}$ & 3 & $3.75 \%$ \\
\hline
\end{tabular}

In this present study omental patch closure was the most commonly performed surgical procedure performed in 46 cases accounting for $57.5 \%$. Appendicectomy was performed in 14(17.5\%) cases. Primary closure was performed in $10(15 \%)$ cases. Ostomies were performed in 7 cases $(8.75 \%)$. Primary closure and diversion stoma was performed in 3 $(3.75 \%)$ cases.

Table-5: Post-operative complications

\begin{tabular}{|l|c|c|}
\hline SSI & 16 & $20 \%$ \\
\hline WOUND DEHISENCE & 6 & $7.5 \%$ \\
\hline ECF & 2 & $2.5 \%$ \\
\hline MORTALITY & 8 & $10 \%$ \\
\hline
\end{tabular}

The most common post-operative surgical complication is that of surgical site infection which occurred in 16 patients accounting for $20 \%$ of cases. Wound dehiscence is seen in 6 patients constituting to $7.5 \%$. Enterocutaneous fistula is seen in 2 patients constituting to $2.5 \%$. 2 cases of ileal perforation.

In this present observational study the overall mortality was observed in 8 patients constituting to $10 \%$. Perforation involving multiple sites carried a $100 \%$ mortality risk followed by ileal and large intestinal perforation with $60 \%$ and $50 \%$ respectively.
Whereas appendicular perforation has no mortality risk in the present study.

\section{DISCUSSION}

This retrospective study was conducted in Kamineni institute of medical sciences, narketpally . The study group consisted of 80 patients diagnosed to have an hollow viscus perforation and underwent surgical treatment during the study period of $1^{\text {st }}$ January 2019 to $31^{\text {st }}$ December 2019.

The age distribution is as shown in Table-2. The highest number of patients encountered in this series was in the age group 41-50 years followed by the age group of 51-60 years. The mean age in this study was 42.6 years. This is comparable with the study by Jhobta RS who studied 504 cases of perforation peritonitis in which the mean age was 36.8 years.

Sex distribution: The ratio of men to women with all types of perforation irrespective of site and pathological condition was 2.07: 1 in the present study.

Different authors have found variable results with regard to sex ratio. Ramesh $\mathrm{C}$ Bharati et al., [5]. Reported sex ratio of $24: 1$ in their review of 50 cases. Mishra SB et al, found an M: F ratio of 49:1.2.

The frequency of anatomical site involved in hollow visceral perforation is as shown in the Table- 3 . The commonest site involved in this study was duodenal ulcer perforation (38.7) followed by gastric perforation (23.7\%) Appendicular perforation (17.5\%) and ileal perforation (12.5\%).

Jhobta RS in his study of 504 cases of perforation peritonitis found duodenum as the commonest site of involvement, followed by appendicitis, gastrointestinal perforation due to blunt trauma abdomen, Typhoid fever and tuberculosis.

\section{CONCLUSION}

The highest number of patients with hollow viscus perforation was seen in the age group 41-50 years, irrespective of the pathological conditions followed by 51-60year age group. Duodenal ulcer perforation was the most common cause of hollow viscous perforation, next commonest was gastric perforation followed by appendicular perforation. Large bowel perforations are rare.

Laparotomy with closure of the perforation with omental patch closure is the commonest method of surgical management of hollow viscous perforation.

Surgical site infection is the most common post-operative complication $(25 \%)$, followed by wound dehiscence $(7.5 \%)$ and enterocutaneous fistula $(2.5 \%)$. Mortality was seen in $10 \%$ of hollow viscous perforation. 


\section{REFERENCES}

1. Rao M, Samee AA, Khan SM. Hollow viscous perforation: a retrospectum study. Intern J Sci Res. 2015 Mar; 6(3):3250-4.

2. Afridi SP, Malik F, Ur-Rahman S, Shamim S, Samo KA. Spectrum of perforation peritonitis in Pakistan: 300 cases Eastern experience. World Journal of Emergency Surgery. 2008 Dec; 3(1):31.

3. Donovan AJ, Berne TV, Donovan JA. Perforated duodenal ulcer: an alternative therapeutic plan. Archives of surgery. 1998 Nov 1;133(11):1166-71.

4. Beniwal US, Jindal D, Sharma J, Jain S, Shyam G. Comparative study of operative procedures in typhoid perforation. Indian J Surg. 2003 Mar $1 ; 65(2): 172-77$
5. Jhobta RS, Attri AK, Kaushik R, Sharma R, Jhobta A. Spectrum of perforation peritonitis in Indiareview of 504 consecutive cases. World journal of Emergency surgery. 2006 Dec;1(1):26.

6. Dandapat MC, Mukherjee LM, Mishra SB, Howlader PC. Gastrointestinal perforations. Indian J Surg. 1991;53(5):189-93.

7. Capoor MR, Nair D, Chintamani MS, Khanna J, Aggarwal P, Bhatnagar D. Role of enteric fever in ileal perforations: An overstated problem in tropics?. Indian journal of Medical microbiology. 2008 Jan 1;26(1):54.

8. Velappan DP, Kaveri S. Clinical study and management of hollow viscus perforation of abdomen. Int Surg J. 2017; 4:1773-6. 